\title{
Are You Ready to Learn from Your Offshore Affiliates?*
}

\author{
Bodo B. Schlegelmilch ${ }^{* *}$, Björn Ambos ${ }^{* * *}$, Tina C. Chini ${ }^{* * * *}$
}

\begin{abstract}
Reverse knowledge transfers are beneficial to MNCs, but just how much so depends on the subsidiaries' strategic mission, its country's economic development and the ability of headquarters to absorb incoming information.

Within MNCs, the traditional role of headquarters as prime source of knowledge and competencies is changing. Increasingly, headquarters act as receivers of knowledge from their internationally dispersed subsidiaries.

The efficiency of the MNC as a knowledge-integrating institution is being influenced by changes in both its subsidiaries' context and its capabilities to process knowledge.
\end{abstract}

Keywords: Multinational Companies; International Subsidiaries; Overseas Knowledge; Intrafirm Knowledge; Reverse Knowledge; Global Economy

\section{Introduction}

Reverse knowledge transfers are beneficial to MNCs, but just how much so depends on the subsidiaries' strategic mission, its country's economic development and the ability of headquarters to absorb incoming information.

Within MNCs, the traditional role of headquarters as prime source of knowledge and competencies is changing.

Increasingly, headquarters act as receivers of knowledge from their internationally dispersed subsidiaries. This study sheds light on critical contingencies that influence headquarters' ability to benefit from their offshore knowledge base.

\footnotetext{
* Adapted from European Business Forum, Issue 16, Winter 2003/4

** Professor and Chair of International Marketing and Management, Vienna University of Economics and Business Administration (bodo.schlegelmilch@wu.ac.at)

*** Lecturer in Marketing, Strategy and Innovation Group, School of Management, The University of Edinburgh (bjoern.ambos@wu.ac.at)

**** Assistant Professor of International Marketing and Management, Vienna University of Economics and Business Administration (tina.chini@wu-wien.ac.at)
}

Edited by: ISTEI - University of Milan-Bicocca

ISSN: 1593-0319

Schlegelmilch Bodo B., Ambos Björn, Chini Tina C., Are You Ready to Learn from Your Offshore Affiliates?, Symphonya. Emerging Issues in Management (symphonya.unimib.it), n. 2, 2003, pp. $27-$ 33

http://dx.doi.org/10.4468/2003.2.03schlegelmich.ambos.chini 
Our findings indicate that the efficiency of the MNC as a knowledge-integrating institution is being influenced by changes in both its subsidiaries' context and its capabilities to process knowledge.

\section{The Study}

Our study is part of a larger research project involving both a qualitative and a quantitative investigation. Following intensive fieldwork, involving detailed interviews and cases studies in more than 38 multinationals, a large scale empirical survey was conducted which supports the conclusions of this article. The sample for the empirical study comprises 294 individual knowledge transfers of 66 overseas subsidiaries to their respective headquarters. The subsidiaries belong to 33 MNCs headquartered in Europe. Participating firms were selected on the basis of their turnover, their degree of internationalisation and their industrial affiliation. First, using the relative contribution of each industry to EU GDP in the year 2000, ten industry quotas were set.

Within each of these quotas, we contacted those firms known to operate at least six overseas subsidiaries (see Harvard definition of MNC, Vernon, 1966). The questionnaire was designed to measure various determinants of headquarters' perceived benefits from subsidiary knowledge. Data were obtained on the strategic mission of the subsidiary, the type, amount and benefit of knowledge transferred, the perceived cultural distance between headquarters and the respective subsidiary, and the absorptive capacity of headquarters. Research hypotheses were subsequently tested using multiple regression. A full operationalisation of the constructs, statistical results, or the research paper can be provided on request.

\section{Accessing Overseas Knowledge}

Managers in the headquarters of multinational companies (MNCs) today recognise the need to access internationally dispersed knowledge. Most scholars, moreover, share the belief that subsidiaries of MNCs are crucial to tap into local 'pockets of knowledge'. As Yves Doz and others put it (1997, p5): "as the leading edge of knowledge creation grows more dispersed, the opportunity cost of relying exclusively on the home base as the source of knowledge and innovation increases." Yet while we already know how subsidiaries attempt to access local knowledge (see Ambos, 2002), our understanding on how firms can best 'learn at the periphery' is still rudimentary. Only a few studies (e.g. Hakanson \& Nobel, 2001) explicitly investigate the incidence of 'reverse knowledge transfers' from the periphery to the headquarters. And, while this literature confirms that subsidiaries provide valuable knowledge for the $\mathrm{MNC}$, most studies do not provide much evidence on what drives the centre's ability to benefit from its offshore affiliates.

Building on these observations, we undertook a study aimed at advancing the state of our theoretical and empirical understanding of 'reverse knowledge transfers'. It represents a first attempt to identify contingencies that determine the benefit of such reverse transfers from the HQ's point of view. 
As knowledge creation gets more dispersed, the assumption of home-base supremacy holds true for fewer and fewer companies. Subsidiaries tap domestic sources of knowledge, which can subsequently be diffused and exploited within the MNC. Two examples from our field studies illustrate this point.

$\square$ Bayer, for example, a German chemical giant traditionally rooted in the chemical and pharmaceutical industries, was early to recognise the potential impact of biotechnology on drug development (actually as early as 1947). Acknowledging that the German headquarters did not possess the necessary skills, Bayer decided to build up research capacities in the emerging Biotech 'clusters' in Berkeley, California and West Haven, Massachusetts. By utilising its affiliates' knowledge and expertise in areas like AIDS, Alzheimer's and blood coagulation, Bayer truly spurred its capabilities for new therapeutics.

$\square$ In a similar way, we found that engineers at Royal Dutch Shell Europe used local knowledge from its Japanese affiliate. Intimate knowledge of local driving conditions helped Shell to develop a superior engine oil for the Japanese market. Notwithstanding the availability of test cars, the distinct characteristics of the Japanese oil market were not initially obvious to the engineers. As one senior manager put it: "When we think of cars, we think of cars that drive. Working with our colleagues in Japan we soon recognised that in Tokyo you have to think of cars that stand for hours in traffic. Changing the properties of our oil gave us a competitive edge not only in Japan, but also in other crowded places."

At first sight, the lessons from these two examples seem to be clear: today's firms increasingly need to access and leverage local knowledge. However, while some companies, such as Canon, Xerox, IBM, McKinsey and Boston Consulting Group (BCG) have already developed excellent transfer mechanisms (see also Asakawa, 2001; Skryme \& Amidon, 1997; Davenport, 1998; Hansen et al., 1999), we still have little information on what determines the benefits to headquarters, for example which type of knowledge is most valuable. Moreover, we have little understanding of what other contingencies influence headquarters' ability to access, leverage and benefit from its offshore affiliates? In the rest of this article, we report on the insights gained from our study.

\section{Benefiting from Intrafirm Knowledge Transfers}

Beneficial knowledge comes in different forms and sizes. Research has gone a long way to distinguish knowledge from information or mere data, to categorise the degree to which pieces of knowledge are tacit - i.e. articulable (Polanyi, 1966) and the extent to which it is embedded - i.e. context specific (Doz \& Santos, 1997). In our study, we decided to follow Gupta and Govindarajan (2000) by asking respondents to indicate the amount of knowledge transferred along six dimensions, ranging from pure data on competitors to higher forms of knowledge like 
technological knowhow. Respondents also indicated how much they benefited from knowledge transfers of the different dimensions. Figure 1 reveals that almost all subsidiaries in our sample engage in some form of 'reverse knowledge transfer'. In absolute terms, knowledge transfers of technical and marketing knowhow occur most often.

Figure 1: Intensity of Reverse Knowledge Transfers by Knowlwdge Type

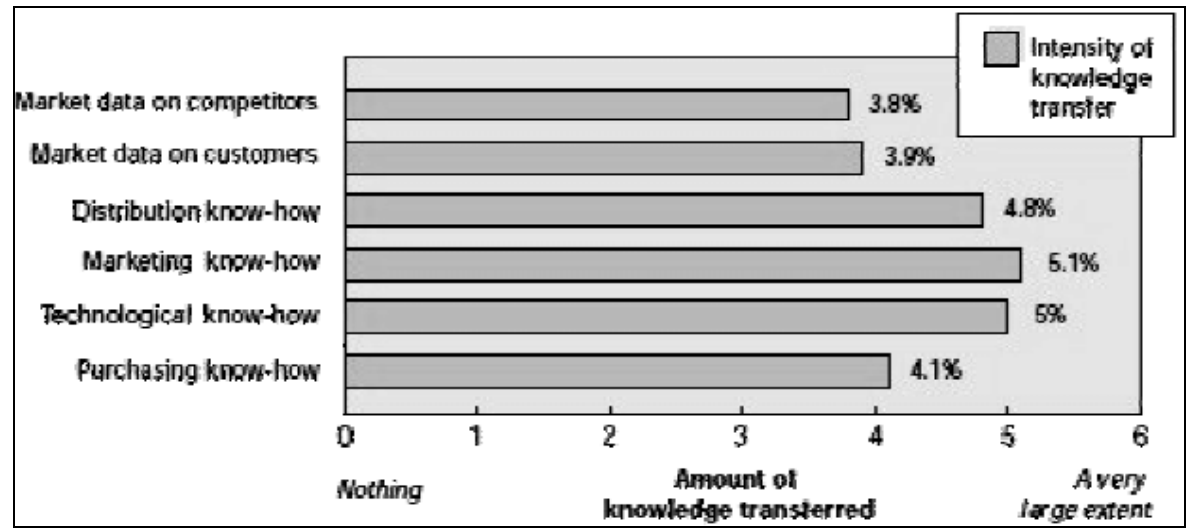

Yet when the focus shifts to the benefits created by this incoming knowledge (Figure 2) it becomes obvious that not all these transfers are viewed as equal. Headquarters seems to profit most of all from data on competitors and customers. With respect to the other four categories, transfer intensity is larger than the derived benefit. Thus, ironically the companies in our sample seem to benefit most from what they get least. Astonishingly, this is not knowledge of a higher order but market data about competitors. One possible explanation might be that the costbenefit relationship is perceived more positively when no complicated processes of decoding and adaptation are involved. Another reason could be the aggressive competitive behaviour of the companies in our sample, which consisted largely of industry leaders.

Figure 2: Benefit of Knowlwdge Vs. Transfer Intensity by Knowlwdge Type

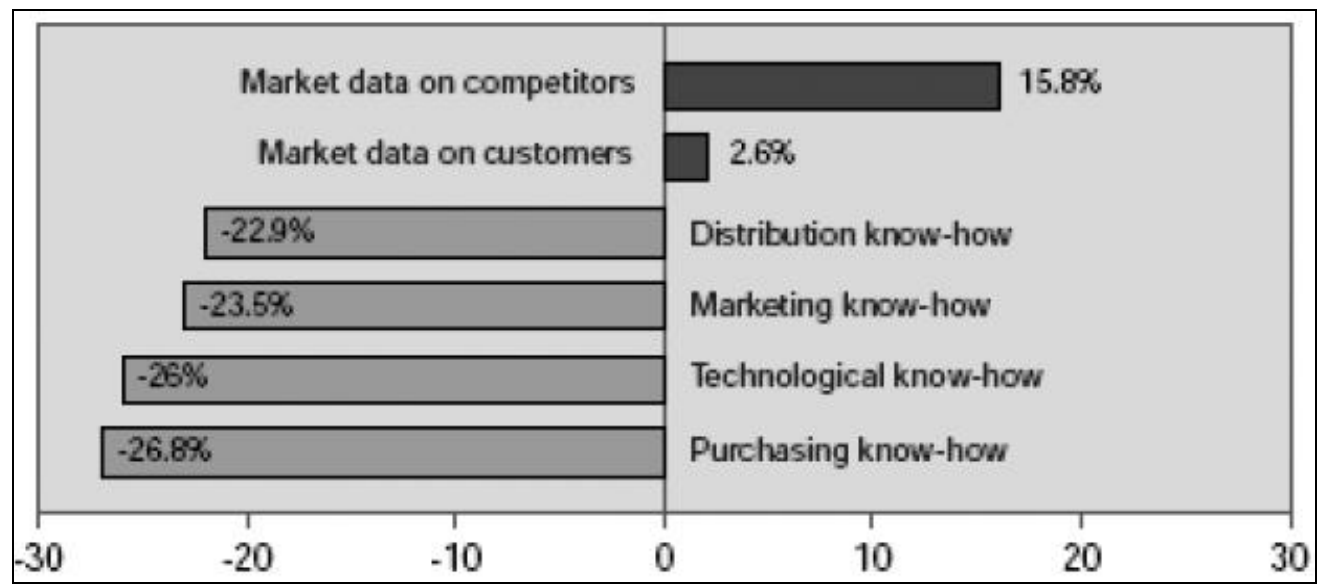




\section{Determining the Benefit of Reverse Knowledge Transfers}

Seeking guidance on what drives the benefits of local knowledge is an important first step for managers located at headquarters. Our research found three primary contingency factors:

- relative host market strength;

- the strategic mandate of the subsidiary;

- headquarters' capacity to absorb incoming knowledge.

\subsection{Relative Host Market Strength}

Michael Porter (1990) and many others showed that knowledge often resides in highly specialised industry clusters. Knowledge originating from subsidiaries located in these 'pockets of innovation' can enhance corporate capabilities. In extensive field studies in several MNCs, we did not find one biotech or pharmaceutical firm that did not invest along the famous Route 128 (a highway in Massachusetts, US), or California's 'Biotech-bays and beaches' in order to benefit from these knowledge clusters. Yet, as our empirical results show, this knowledge sourcing does not only prevail in high-tech sectors. In all industries, from consulting services to oil drilling equipment, we observe that headquarters profits in particular from subsidiaries located in a relevant lead market. On a broader level, our results clearly confirm that knowledge predominantly flows from highly developed to less developed regions. A headquarters' benefit from subsidiaries located in such lead markets was significantly higher than that derived from subsidiaries in less developed markets.

\subsection{Subsidiary Mandate}

For some time academics and practitioners alike have pointed out that individual subsidiaries may possess different and distinct mandates (Ghoshal \& Bartlett, 1990; Martinez \& Jarillo, 1991; Ghoshal \& Nohria, 1989; Gupta \& Govindarajan, 1991; White \& Poynter, 1984; Birkinshaw \& Morrison, 1995). In fact, these subsidiary mandates or charters can become very complex. Scholars have distinguished between different levels of competencies, the strategic importance of the environment, the autonomy granted to the subsidiary, its interdependence with other network actors, as well as its market orientation (Birkinshaw \& Morrison, 1995).

Thus, some subsidiaries are mandated to contribute to the MNC by generating and disseminating new knowledge, while the primary aim of others may be to implement or exploit headquarters' knowledge in the local context. As a consequence, the extent to which headquarters will benefit from local knowledge will depend on this mission. Following Gupta and Govindarajan (1991) and Schlegelmilch and Chini (2003), we identified four distinct mandates: 'Global Innovators', 'Integrated Players', 'Implementers', and 'Local Innovators'. Two of these mandates, 'Global Innovators' and 'Integrated Players', are generally seen as the lead units. They generate knowledge of high value for the MNC and are heavily engaged in intrafirm knowledge transfers (Gupta \& Govindarajan, 1991). Thus, 
given their strategic task, we assume this knowledge to be most beneficial for headquarters. The two other mandates play a less prominent role when it comes to reverse transfers 'Implementers' are charged with a clear mandate to implement corporate strategy, whereas 'Local Innovators' operate in idiosyncratic markets that offer few opportunities for reverse knowledge transfers. In both cases, knowledge is seldom transferred back to corporate headquarters, and the benefits of such transfers are likely to be relatively low. These categories, of course, are not set in stone.

\begin{abstract}
$\square$ In order to tap local sources of knowledge, for example, Shiseido a cosmetics company with headquarters in Japan - decided to augment its French Gien factory's mandate because the company considered France to be the lead country in the fragrance business (Asakawa, 2001). As a result, the French subsidiary was assigned asignificant role as knowledge creator, closely linked to local suppliers and specialists.
\end{abstract}

The results of our study clearly confirm the above patterns. Our data demonstrate that from a headquarters' point of view, knowledge received from 'Integrated Players' is most valuable. In this respect, our results add to the recent literature on centres of excellence of corporate leaders (Moore \& Birkinshaw, 1998; Holm \& Pedersen, 2000) which similarly emphasises the strategic importance of these units.

As most authors analyse knowledge inflows - not benefits - our results extend and support these findings on a higher level.

\title{
5.3 Absorptive Capacity
}

The third major determinant of the benefits derived from reverse knowledge transfers is the headquarters' own capability to absorb incoming knowledge. Cohen and Levinthal (1990) define absorptive capacity as the ability to use prior knowledge, to recognize the value of new information, assimilate it, and apply it to create new knowledge and capabilities. If prior knowledge in a certain area exists at headquarters, managers will better understand and apply incoming knowledge.

Moreover, the headquarters will also be able to assess the value of knowledge more critically, as managers are more familiar with the topic. Empirically, our results confirm this pattern. To be of value, incoming knowledge has to be related to, but also needs to be different from, existing headquarters knowledge. The importance of absorptive capacity cannot be overemphasised. This result is of clear practical relevance as it demonstrates that not all attempts to source local knowledge will be successful. Those lacking the capability to understand local knowledge will not benefit.

\section{The Myth of Distance}

While a number of studies propose that knowledge transfer might be influenced by either distance or (its opposite) context similarity (Barkema \& Vermeulen, 1997; Bhagat et al., 2002; Tenkasi, 2000), our data conveys a different message. Although we use several different measures of distance, such as cultural and 
organisational, none of them was significantly related to the headquarters' knowledge benefits. At this stage we can only speculate why. It is plausible that with respect to context similarities, two contradictory forces are at work. On the one hand, knowledge residing in culturally and organisationally distant subsidiaries might be of higher benefit to headquarters in that it is less redundant. In the case of Shell, knowledge residing in its Japanese subsidiary was highly beneficial simply because it provided clues from a very different context. On the other hand, it is reasonable to assume that knowledge residing in a very dissimilar context will also be harder to transfer. Doz et al. (2001) describe the tremendous difficulties experienced by Shiseido, a Japanese cosmetics firm, in its attempts to appropriate knowledge on perfumes from its French operations. Despite considerable efforts, all perfumes turned out to smell more like miso soup than French perfume. Knowledge on the creation of a new fragrance is highly locally embedded, also called 'existential' (Doz and Santos, 1997), and thus hard to transfer. In the transmission process, some of the benefits might be destroyed due to 'noise'. Thus, these two forces could explain why our quantitative study does not show any effects at the bottom line. Shiseido, for example, only succeeded after moving its product development entirely to France and hiring one of the famous French 'noses' (Doz et al. 2001).

\section{The Management Challenge}

All our findings show that reverse knowledge transfers in MNCs are beneficial to headquarters. However, transferring this insight into practice is not always easy. A central question in the current debate on value creation in the MNC is to what extent, and through which determinants, headquarters benefit from knowledge transfers stemming from their offshore affiliates. In this article we have tried to shed light on several factors influencing headquarters' ability to 'learn from the periphery'. Our results show that the benefit depends on the subsidiaries' strategic mission, the economic development of the source country, as well as the absorptive capacity of the headquarters. Context similarity, in turn, had no significant impact on the benefits of knowledge transfer. Managers who have to shape the global knowledge management processes of their firms should note that more knowledge inflow does not necessarily lead to more benefits. Incoming knowledge is filtered according to certain criteria. Thus, a contingency approach, which treats different sources of knowledge differently, might be warranted. In this respect, managers may find it most convenient to focus on strategic lead units, as it is their knowledge that respondents to the study rate as most beneficial. Managers at headquarters should ensure that this type of knowledge inflow receives the organisational attention necessary to extract all valuable information. Second, given the discrepancy of the (low) amount of competitor data transferred compared to the benefits of this knowledge, reporting routines should be designed in such a way that competitor information is requested on a regular basis. In addition, our results confirm the importance of headquarters' own (prior) knowledge in the field. In other words, while local knowledge might be potentially beneficial, firms trying to rely fully on subsidiary knowledge are bound to fail as a result of their inability to utilise this knowledge properly. 